Journal of Advanced Research in Fluid Mechanics and Thermal Sciences

Journal homepage: www.akademiabaru.com/arfmts.html ISSN: 2289-7879

\title{
Exergoeconomic Analysis of 21.6 MW Gas Turbine Power Plant in Riau, Indonesia
}

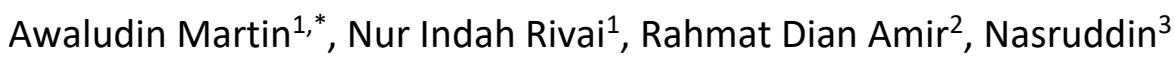 \\ Mechanical Engineering Department, Riau University, Kampus Bina Widya, Simpang Baru, Pekanbaru, 28293, Indonesia \\ PLN UPDK Pekanbaru, Pekanbaru's Power Plant Unit Control, National Electricity Company, Pekanbaru, 28144, Indonesia \\ Mechanical Engineering Department, University of Indonesia, Kampus UI, Depok, 16424, Indonesia
}

\section{ARTICLE INFO}

\section{Article history:}

Received 27 January 2021

Received in revised form 25 May 2021

Accepted 2 June 2021

Available online 2 July 2021

\section{Keywords:}

Exergy; exergoeconomic; exergy destruction; total cost loss

\section{ABSTRACT}

In this study, exergoeconomic analysis was carry out on a $21.6 \mathrm{MW}$ gas turbine power plant by using logbooks record Pekanbaru Unit. The exergy analysis was start to determine the exergy destruction of each component of the power plant based on the first and second laws of thermodynamics and in this study, exergy and economic analysis were combined and used to evaluate the accrued cost caused by irreversibility, including the cost of investment in each component. The exergy analysis results showed that the location of the largest destruction was in the combustion chamber with $21,851.18 \mathrm{~kW}$, followed by the compressor and gas turbine with $8,495.48 \mathrm{~kW}$ and $3,094.34 \mathrm{~kW}$, respectively. The economic analysis resulted that the total cost loss due to exergy destruction was $2,793.14 \$$ /hour, consisting of compressor $1,066.43 \$ /$ hour, combustion chamber $1,561.46 \$$ /hour and gas turbine $165.25 \$ /$ hour. The thermal and exergetic efficiency of gas turbine power plant were $24.51 \%$ and $22.73 \%$ respectively.

\section{Introduction}

The increase in population, economic growth and industrial expansion have led to higher energy demands, including electricity. However, these demands are not accompanied by increased availability of energy especially fossil energy. This has led to the uncertainty in energy prices and increasing stringent emission regulations. Therefore, researchers and industries are encouraged to discover more efficient energy systems with reduced thermal energy losses [1-7].

The evaluation of thermal energy systems and economic principles is very important for researchers and industries to improve its efficiency and reduce operating costs. Currently, the method applied in analyzing energy conversion in a system operates based on the concept of the first law of thermodynamics know as energy analysis which however, cannot be used to calculate the efficiency and losses precisely [8].

However, exergy analysis was carried out based on the first and second laws of thermodynamics. It was used to determine the magnitude, location, cause of irreversibility and to discover the

\footnotetext{
* Corresponding author.

E-mail address: awaludinmartin01@gmail.com
}

https://doi.org/10.37934/arfmts.84.1.126134 
efficiency of the power plant components. The essence of this analysis is primarily for optimization of thermal energy system, which in this case is the power plant [1,9-13]. Furthermore, in this study, exergy and economic analysis were combined and used to evaluate the accrued cost caused by irreversibility, including the cost of investment in each component. This combination is known as exergoeconomic analysis $[12,14]$.

Exergoeconomic analysis on thermal energy system especially in power plants has previously been discussed and carried out by several authors. An exergoeconomic analysis of $600 \mathrm{MW}$ steam power plant was carried out and discovered that the boiler has the highest amount of exergy destruction therefore, greater attention needs to be allocated to it in terms of design and technical change, because about $42 \%$ of exergy supplied is lost in the steam generator [8]. Furthermore, an investigated of geothermal power plant $110 \mathrm{MW}$ based on exergy and exergoeconomic analysis and it was discovered that the highest exergy destruction was $58,263 \mathrm{~kW}$ from reinjection wells, which is about $21.25 \%$ of the production wells exergy [15].

exergoeconomic analysis of a 100 MW Unit GE Frame 9 Gas Turbine Plant in Ughelli, Nigeria was performed on engineering equation solver (EES) software and the resulting plant thermal efficiency was $31.05 \%$. Furthermore, the overall exergy efficiency of $30.81 \%$, identified that the lowest exergetic efficiency (54.05\%) was in the combustion chamber [14]. A similar study of exergoeconomic analysis was carried out for gas turbine power plant and the highest exergy destruction cost obtained was also in the combustion chamber compared with other component $[5,9,11,12,16]$.

In this study, exergetic and economic analysis were performed for the $21.6 \mathrm{MW}$ gas turbine power plant where the scheme of power plant is show in Figure 1. This Study aim to investigate the performance of gas turbine power plant, identify the location of the largest exergy loss, and identify the total cost loss due to exergy destruction.

\section{Methodology}

The gas turbine power plant of $21.6 \mathrm{MW}$ used was an open-cycle single shaft system and located at Pekanbaru, Riau-Indonesia. Furthermore, natural gas with low heating value ( $\mathrm{LHV}=50,017.5 \mathrm{KJ} / \mathrm{Kg}$ ) was used as fuel. The system consists of an Air-Compressor (AC), Combustion Chamber (CC) and Gas Turbine (GT). The Schematic of the gas turbine power plant is shown in Figure 1.

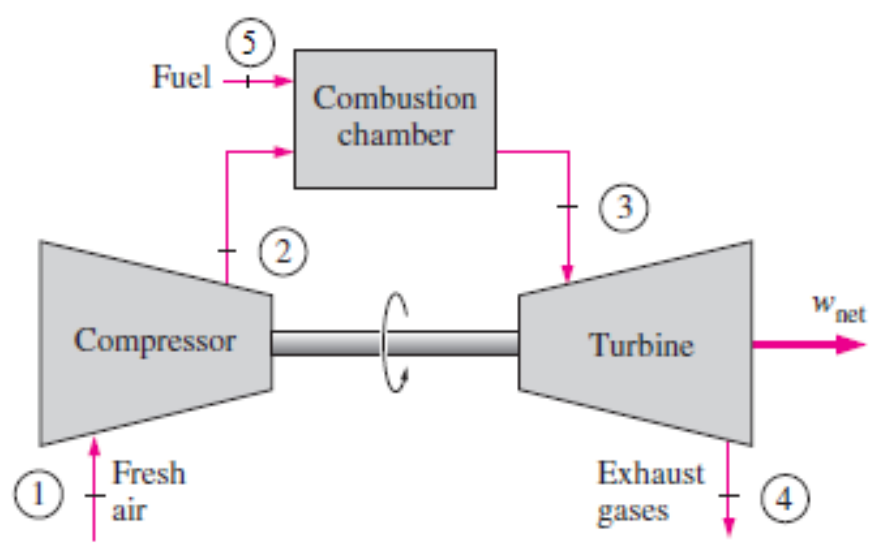

Fig. 1. Schematic of gas turbine power plant [17] 


\subsection{Data Collection}

Data such as daily power generated, temperature, pressure and mass flow rate of working fluids including natural gas composition for exergy analysis were collected from the gas turbine power plant's record log books for five days. The air temperature and pressure inlet to compressor were $320 \mathrm{~K}$ and 1.01325 bar respectively.

\subsection{Exergy Analysis}

Exergy is a measure of the energy quality, which can be destroyed in thermal systems due to its irreversibility. The second law of thermodynamics uses an exergy balance in the analysis of thermal systems. It is also defined as the maximum work produced from initial to dead conditions. Meanwhile, extermination of exergy is a function of entropy generation, which is defined as a measure of the randomness of a system $[17,18]$.

In addition, exergy refers to the energy utilized by the system to do work. In a steam from a fluid, it is the energy carried in that flow through a process that only interacts with the environment. Total exergy of a system can be generally divided into physical exergy (thermos mechanical) $\mathrm{X}^{\mathrm{PH}}$, kinetic exergy $X^{\mathrm{KN}}$, potential exergy $\mathrm{X}^{\mathrm{PT}}$, and chemical exergy $\mathrm{X}^{\mathrm{CH}}[17,18]$

$X=X^{P H}+X^{K N}+X^{P T}+X^{C H}$

Kinetic and potential exergy were ignored in the system therefore, both exergies were assumed zero. Physical exergy was illustrated with the simple case of an ideal gas. Furthermore, by using the relationship between enthalpy (h) and entropy (s), the equation of physical exergy is as follows

$\dot{X}^{P H}=C_{p}\left[\left(h_{i}-h_{o}\right)-T_{o}\left(s_{i}-s_{0}\right)\right]$

where

$s_{i}-s_{0}=C_{p} \ln \left(\frac{T_{1}}{T_{0}}\right)-R \ln \left(\frac{P_{1}}{P_{0}}\right)$

Heat specific is obtained by polynomial form as a function of temperature as given [17]

$\overline{C_{p}}=a+b T+c T^{2}+d T^{3}$

In a gas turbine power plant, there is no chemical reaction or combustion in the turbine and compressor. Therefore, the chemical exergies in both components were considered zero. An approximation equation for chemical exergy $\left(e_{f}^{C H}\right)$ using hydrocarbons as fuels is given as $\mathrm{C}_{\mathrm{a}} \mathrm{H}_{\mathrm{b}}$ [17]

$e_{f}^{C H} \cong\left(1,033+0,0169 \frac{b}{a}-\frac{0,0698}{a}\right) \cdot L H V$

Exergy destruction of each component is given by

$\dot{X}_{D}=X_{\text {in }}-X_{\text {out }}$

The exergetic efficiency of each component of the gas turbine power plant is given as 
$\eta_{I I}=\frac{X_{\text {out }}}{X_{\text {in }}}$

Furthermore, the equation used to calculate the inlet and outlet of exergy rate, destruction and efficiency, is shown in Table 1.

Table 1

Exergy existing equilibrium of each component

\begin{tabular}{lllll}
\hline Comp. & $\begin{array}{l}\dot{X}_{\text {In }} \\
(M W)\end{array}$ & $\begin{array}{l}\dot{X}_{\text {out }} \\
(M W)\end{array}$ & $\begin{array}{l}\dot{X}_{D} \\
(M W)\end{array}$ & $\begin{array}{l}\eta_{I I} \\
(\%)\end{array}$ \\
\hline $\mathrm{AC}$ & $\dot{W}_{c}+\dot{X}_{1}$ & $\dot{X}_{2}$ & $\dot{W}_{c}+\dot{X}_{1}-\dot{X}_{2}$ & $\frac{\dot{X}_{2}}{\dot{W}_{c}+\dot{X}_{1}}$ \\
CC & $\dot{X}_{2}+\dot{X}_{5}$ & $\dot{X}_{3}$ & $\dot{X}_{2}+\dot{X}_{5}-\dot{X}_{3}$ & $\frac{\dot{X}_{3}}{\dot{X}_{2}+\dot{X}_{5}}$ \\
GT & $\dot{X}_{3}$ & $\dot{X}_{4}+\dot{W}_{G T}$ & $\dot{X}_{3}-\left(\dot{X}_{4}+\dot{W}_{G T}\right)$ & $\frac{\left.\dot{X}_{4}+\dot{W}_{G T}\right)}{\dot{X}_{3}}$ \\
\hline
\end{tabular}

\subsection{Exergoeconomic Analysis}

Exergoeconomic analysis is a combination of exergy analysis with economic principles to provide information for designers or operators that are not available through energy analysis or conventional economic evaluations. It is seen as a form of exergy with a minimum cost. The purpose of carrying out this analysis is to minimize exergy costs. In determining the exergy costs, the cost for each exergy flow is first obtained, followed by separately calculating the costs of each product produced by a system and optimizing various specific variables in a single component or the overall system [19]. The assumptions to facilitate the calculation are as follows

i. Gas turbine power plant lifetime $(n)$ of 24 years

ii. Total operating time $(\mathrm{H})$ of 8760 hours per year

iii. Interest rate (i) of $7 \%$

\subsection{Purchase Equipment Cost, PEC}

This is the cost of purchasing equipment for each component. It was adjusted to the standard based on Bejan et al., [19].

\section{Purchase Equipment Cost of Compressor}

$P E C_{c}=\left[\frac{71,1 \dot{m}_{a}}{0,9-\eta_{c}}\left(\frac{P_{2}}{P_{1}}\right) \ln \left(\frac{P_{2}}{P_{1}}\right)\right]$

Purchase Equipment Cost of Combustion Chamber

$P E C_{c c}=\left[\left(\frac{46,08 \dot{m}_{a}}{0,995-\frac{P_{3}}{P_{2}}}\right)\left(1+\exp \left(0,018 T_{3}-26,4\right)\right]\right.$

Purchase Equipment Cost of Gas Turbine

$P E C_{g t}=\left[\left(\frac{479,34 \dot{m}_{g}}{0,92-\eta_{g t}}\right) \ln \left(\frac{P_{3}}{P_{4}}\right)\left(1+\exp \left(0,036 T_{3}-54,4\right)\right]\right.$ 


\subsection{Annual Levelized Cost, $\dot{\mathrm{C}}_{k}$}

Annual levelized cost is the cost of purchasing component equipment completeness minus the loss value per unit time, as in the following equation

$$
\dot{\mathrm{C}}_{k}=\left[\left(P E C-\frac{0,1}{(1+i)^{n}}\right)\left(\frac{i}{1-\frac{1}{(1+i)^{n}}}\right)\right]
$$

Eq. (11) is used for the conversion of capital investment cost into cost per unit time, $Z_{k}$, using relationship between maintenance factor $(\varnothing)$ is assumed 1,06 [19] and operating time per year $(H)$

$Z_{k}=\frac{\phi x \dot{\mathrm{C}}_{k}}{H}$

Exergy costs require a variety of cost equilibrium usually formulated for each component. Cost equilibrium is applied to component $\mathrm{k}$ indicating that the total cost associated with all exergy outflow rates $\left(\Sigma_{e} \dot{\mathrm{C}}_{e . k}\right.$ and $\left.\dot{\mathrm{C}}_{w . k}\right)$ is equal to the sum of the cost levels of all incoming exergy rates $\left(\Sigma_{i} \dot{\mathrm{C}}_{i . k}\right)$ plus various fixed financing due to investment and maintenance costs $\left(\dot{Z}_{k}\right)$. Therefore, for systems that receive heat and produce work, exergy equilibrium is written as

$\Sigma_{e} \dot{\mathrm{C}}_{e . k}+\dot{\mathrm{C}}_{w . k}=\Sigma_{i} \dot{\mathrm{C}}_{i . k}+\dot{\mathrm{Z}}_{k}$

The equation simply states that the total cost of the various exergy outgoing rates is equal to the total expenditure required to produce the exergy i.e. the costs of the various exergy entry points plus capital costs and others. Furthermore, the various exergy rates (Xi, $\dot{W}$ and $\mathrm{Xe})$ which enter and exit the $\mathrm{k}$ component were calculated in the analysis carried out in the previous stage. Therefore, the equation can be written as

$\Sigma_{e}\left(C_{e} X_{e}\right)_{k}+\dot{\mathrm{C}}_{w . k} \dot{\mathrm{W}}_{k}=\Sigma_{i}\left(C_{i} X_{i}\right)_{k}+\dot{\mathrm{Z}}_{k}$

Assuming that the above exergy loss through supply of additional fuel $\left(X_{f, k}\right)$ to component $\mathrm{k}$ and the average cost $\left(C_{F, k}\right)$ of supplying the exergy unit remains constant with varying losses within the component $\mathrm{k}$, the destruction costs $\left(\dot{\mathrm{C}}_{D, k}\right)$ can then be written as

$\dot{\mathrm{C}}_{D, k=} C_{F, k} \cdot X_{f, k}$

\section{Results}

Physical properties and chemical exergy which flowed at various state points in the gas turbine power plant as shown in Table 2 were calculated based on the values of measured properties, such as temperature $(\mathrm{k})$, pressure (bar), heat capacity $(\mathrm{kj} / \mathrm{kg} \mathrm{K}$ ) and mass flow rate $(\mathrm{kg} / \mathrm{s})$. By using the equation shown in Table 1 and values in Table 2, the inlet and outlet of exergy rate, exergy destroy and exergy efficiency were calculated and the results are shown in Figure 2. 


\section{Table 2}

Physical properties and chemical exergy flows at various state points (for state number refer to Figure 1)

\begin{tabular}{llllllll}
\hline State & $\mathrm{T}$ & $\mathrm{P}$ & $\mathrm{Cp}$ & $\dot{m}$ & $\begin{array}{c}\dot{X}^{P H} \\
(M W)\end{array}$ & $\begin{array}{c}\dot{X}^{C H} \\
(M W)\end{array}$ & $\begin{array}{c}X \\
(M W)\end{array}$ \\
\hline 1 & 320 & 1.013 & 1.007 & 94.15 & 0 & 0 & 0 \\
2 & 590 & 5.88 & 1.05 & 94.15 & 23.8 & 0 & 23.8 \\
3 & 1110 & 5.7 & 1.25 & 95.46 & 70.7 & 0 & 70.7 \\
4 & 723 & 1.013 & 1.13 & 95.46 & 19.7 & 0 & 19.7 \\
5 & 302 & 14.84 & 2.21 & 1.31 & 1.12 & 67.5 & 68.7 \\
\hline
\end{tabular}

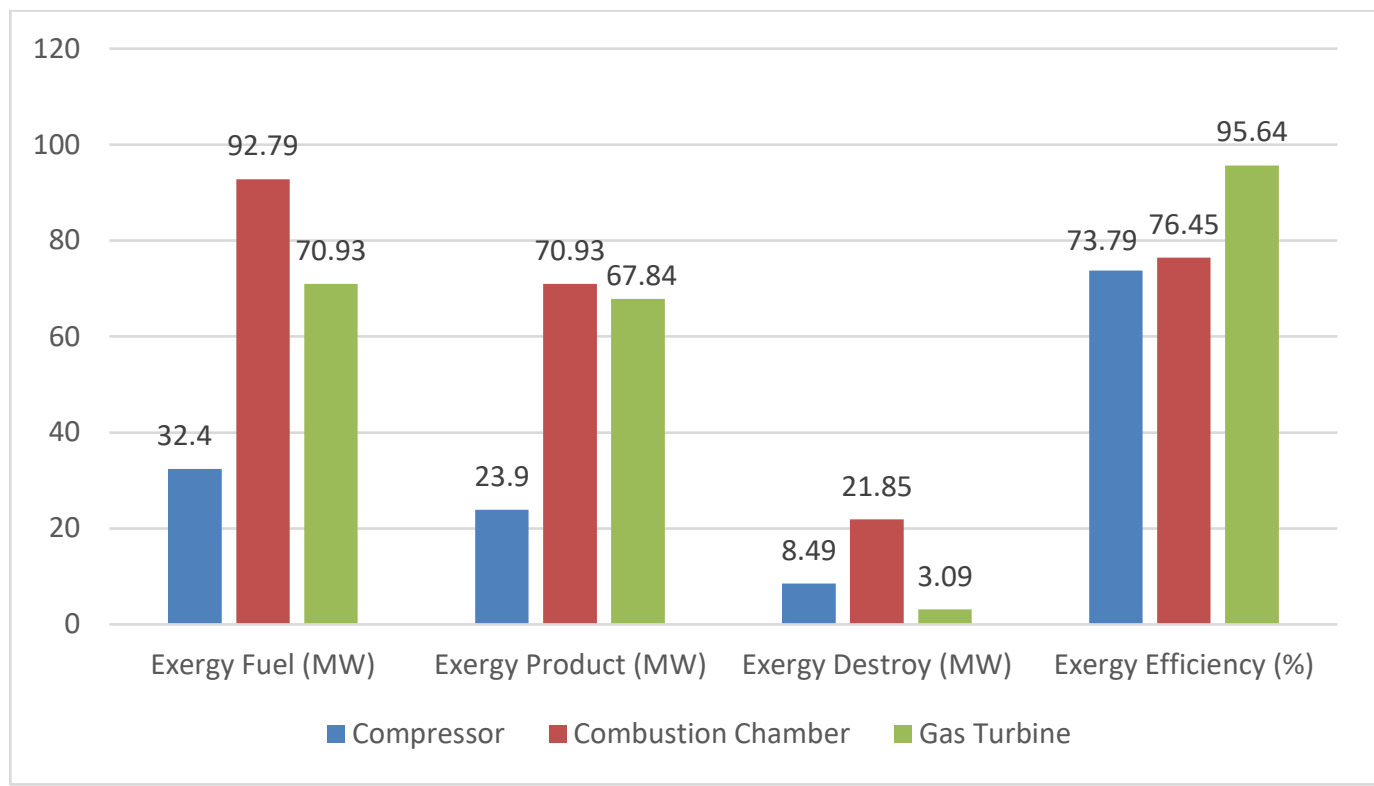

Fig. 2. Exergy rate, exergy destroy, and exergetic efficiency in each component

The percentage of exergy input and loss in each of component and the output based on the results of the analysis is shown in Figure 3 Grassman diagram of gas turbine power plant.

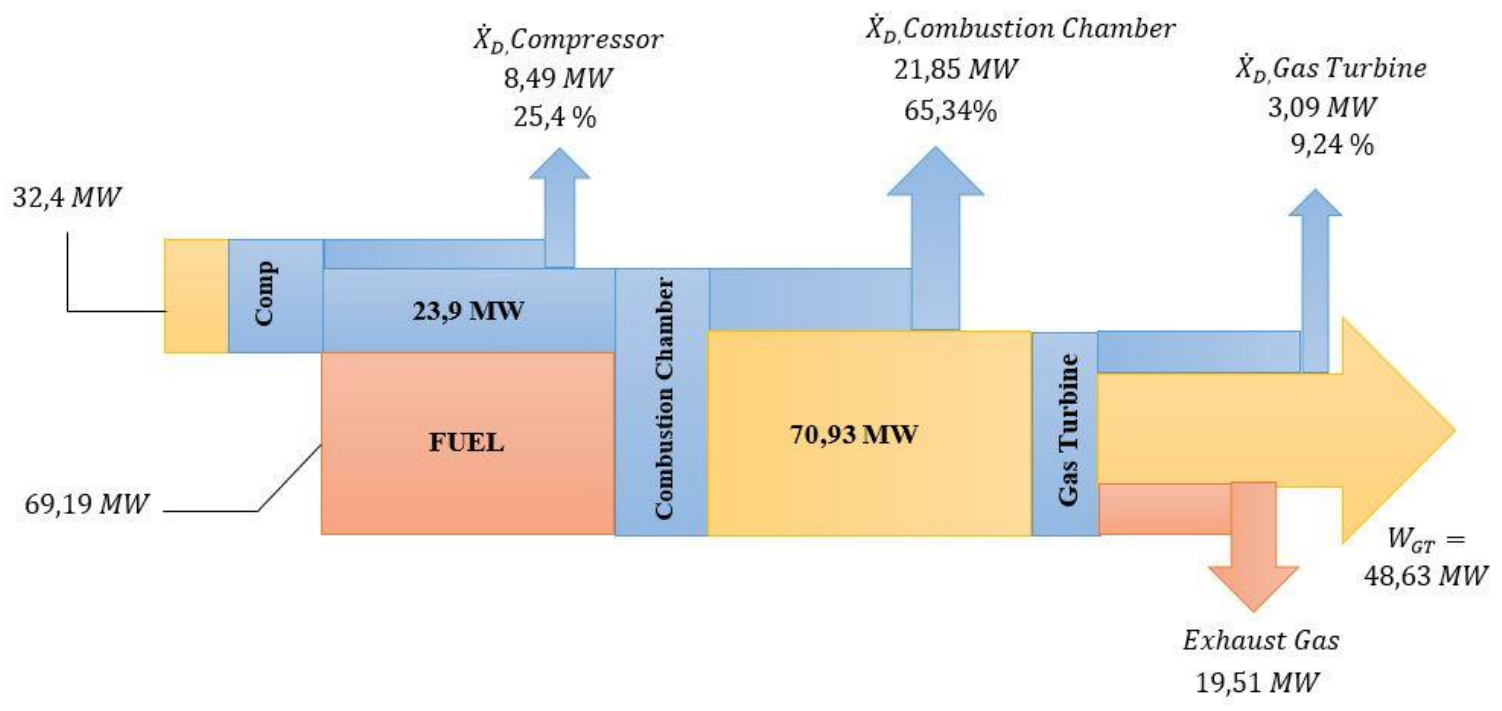

Fig. 3. Grassmann diagram of gas turbine power plant 
By using Eq. (8)-(15) and data from Table 2, exergoeconomic of gas turbine for each component were calculated and the results are shown in Table 3.

Table 3

Gas turbine components exergoeconomic analysis

\begin{tabular}{lllllllll}
\hline Component & $\dot{X}_{\text {in }}$ & $X_{\text {out }}^{\cdot}$ & $\dot{X}_{D}$ & $P E C$ & $\dot{C}_{k}$ & $\dot{Z}_{k}$ & $c$ & $\dot{C}_{D}$ \\
& $(M W)$ & $(M W)$ & $(M W)$ & $(\$)$ & $(\$ /$ year $)$ & $(\$ / h r)$ & $(\$ / k W h)$ & $(\$ / h r)$ \\
\hline Compressor & 32.40 & 23.90 & 8.49 & $3,421,229.46$ & 188,763 & 22.84 & 0.12 & $1,066.43$ \\
Comb. Chamber & 92.79 & 70.93 & 21.85 & $174,360.79$ & $9,620.22$ & 1.16 & 0.07 & $1,561.46$ \\
Gas Turbine & 70.93 & 67.84 & 3.09 & $2,642,389.59$ & $145,791.90$ & 17.64 & 0.05 & 165.25 \\
\hline
\end{tabular}

\section{Discussion}

Figure 2 and Figure 3 show the exergy destruction of the compressor, combustion chamber and gas turbine. It was seen that the largest exergy destruction occurred in the combustion chamber with $21.85 \mathrm{MW}$ (65.34\%), followed by the compressor with $8.49 \mathrm{MW}(25.4 \%)$, and the smallest was the gas turbine with $3.09 \mathrm{MW}$ (9.24\%). Furthermore, the efficiency of exergy was said to be the same with the efficiency of the second thermodynamic law. Figure 2 showed that the exergy efficiency of the compressor, combustion chamber and gas turbine were $73.79 \%, 76.45 \%$ and $95.64 \%$, respectively. However, the high exergy destruction rate in the combustion chamber was due to unburnt fuel, incomplete combustion and heat loss to the surrounding area through the combustion process $[20,21]$. A similar study was carried out an exergoeconomic analysis on a $100 \mathrm{MW}$ GE gas turbine and the results showed that extermination of exergy in the compressor, combustion chamber and gas turbine were 9.66 MW (3.53\%), 238.7 MW (86.38\%) and 27.97 MW (10.12\%) [14].

The exergoeconomic analysis was calculated by using exergy analysis data and economic principle. It is used to obtain the exergy destruction and cost of each component of gas turbine power plant. Furthermore, the purchased equipment cost of each component as show in Table 3 such as compressor, combustion chamber and gas turbine were calculate by using data from Table 2 and Eq. (7)-(9). It was seen in Table 3 that the most expensive of purchase equipment cost is compressor $\$ 3,421,229.46$ followed by the gas turbine $\$ 2,642,389.59$ and the cheapest was combustion chamber $\$ 174,360.79$ and the total of purchace equipment cost wass $\$ 6,237,979.84$. Caused of the highest exergy destruction rate in the combustion chamber followed by compressor and gas turbine, thus the highest of exergy cost destroy was combustion chamber $\$ 1,561.46$ followed by compressor and gas turbine were $\$ 1,066.43$ and $\$ 165.25$ respectively. In addition, several studies have been carried on exergy analysis of gas turbine power plant and the results are show in Table 4.

Table 4

Exergy destruction rate and exergetic efficiency comparison with other reference

\begin{tabular}{lllllll}
\hline Reference & \multicolumn{3}{c}{ Exergy Destroy $\left(\dot{X}_{D}\right)$} & \multicolumn{3}{c}{ Exergy Cost Destroy $\left(\dot{C}_{D}\right)$} \\
& $(M W)$ & & & $A C$ & $C C$ & $G T$ \\
\hline Ogbe [5] & AC & $C C$ & $G T$ & $A C)$ & 50.99 \\
Aliu, [9] & 1.60 & 64.14 & 2.08 & 42.51 & 531.08 & 29.60 \\
Igbong, [14] & 10.81 & 110.9 & 2.08 & 172.5 & 1566.9 & 385.78 \\
Khademi, [16] & 9.66 & 238.7 & 27.97 & 235.8 & 941.02 & 2118.15 \\
Al Ansi, [21] & 15.32 & 126.6 & 18.56 & 1907.6 & 11622.6 & 385.78 \\
\hline
\end{tabular}

According to the results of exergoeconomic analysis in Table 3, the exergy product from operating the gas turbine power plant for an hour comprised of four component of price electricity. They include capital cost of $0.0134 \$ / \mathrm{kWh}$, fixed operation and maintenance cost of $0.0045 \$ / \mathrm{kWh}$, variable 
operation and maintenance cost of $0.0009 \$ / \mathrm{kWh}$, fuel consumption cost of $0.0864 \$ / \mathrm{kWh}$ and total electricity generated by the gas turbine power of $0.105 \$ / \mathrm{kWh}$ or 10.5 percent USD $/ \mathrm{kWh}$.

\section{Conclusions}

From the analysis results, the thermal and exergetic efficiency of gas turbine power plant were $24.51 \%$ and $22.73 \%$ respectively. In addition, the location of the largest exergy loss was in the combustion chamber with $21,851.18 \mathrm{~kW}$, followed by the compressor with $8,495.48 \mathrm{~kW}$ and the gas turbine with $3,094.34 \mathrm{~kW}$. Meanwhile, the total cost loss due to exergy destruction was $2,793.14 \$$ /hour, consisting of compressor $1,066.43 \$$ /hour, combustion chamber $1,561.46 \$ /$ hour and gas turbine $165.25 \$$ /hour.

\section{References}

[1] Yuksel, Burak, Huseyin Gunerhan, and Arif Hepbasli. "Assessing Exergy-Based Economic and Sustainability Analyses of a Military Gas Turbine Engine Fueled with Various Fuels." Energies 13, no. 15 (2020): 3823. https://doi.org/10.3390/en13153823

[2] Calise, F., M. Dentice d'Accadia, and A. Piacentino. "Exergetic and exergoeconomic analysis of a renewable polygeneration system and viability study for small isolated communities." Energy 92 (2015): 290-307. https://doi.org/10.1016/i.energy.2015.03.056

[3] Al Moussawi, Houssein, Farouk Fardoun, and Hasna Louahlia-Gualous. "Review of tri-generation technologies: Design evaluation, optimization, decision-making, and selection approach." Energy Conversion and Management 120 (2016): 157-196. https://doi.org/10.1016/i.enconman.2016.04.085

[4] Valencia Ochoa, Guillermo, Carlos Acevedo Peñaloza, and Jorge Duarte Forero. "Thermo-economic assessment of a gas microturbine-absorption chiller trigeneration system under different compressor inlet air temperatures." Energies 12, no. 24 (2019): 4643. https://doi.org/10.3390/en12244643

[5] Ogbe, Otujevwe P., Nnamdi B. Anosike, and Ugochukwu C. Okonkwo. "Probabilistic Exergoeconomic Analysis of Transcorp Power Plant Ughelli." (2016). https://doi.org/10.20944/preprints201609.0054.v1

[6] Martin, Awaludin, A. Prayitno, and I. Kurniawan. "Exergy analysis of gas turbine power plant $20 \mathrm{MW}$ in PekanbaruIndonesia." Exergy 7, no. 5 (2016). https://doi.org/10.14716/iitech.v7i5.1329

[7] Nasruddin, Syaiful Nasution, Nyayu Aisyah, Arief Surachman, and Agung Satrio Wibowo. "Exergy analysis and exergoeconomic optimization of a binary cycle system using a multi objective genetic algorithm." Exergy 9, no. 2 (2018). https://doi.org/10.14716/iitech.v9i2.1040

[8] Rakesh Dang, S.K. Mangal, Gaurav. "Exergoeconomic Analysis of 600 MW Thermal Power Plant." SSRG International Journal of Thermal Engineering ( SSRG - IJTE ) 2, no. 1 (2016). https://doi.org/10.14445/23950250/IJTE-V213P101

[9] Aliu, S. A., and P. I. Ochornma. "Exergoeconomic analysis of Ihovbor Gas Power plant." Nigerian Journal of Technology 37, no. 4 (2018): 927-935. https://doi.org/10.4314/nit.v37i4.10

[10] Kaushik, S. C., V. Siva Reddy, and S. K. Tyagi. "Energy and exergy analyses of thermal power plants: A review." Renewable and Sustainable energy reviews 15, no. 4 (2011): 1857-1872. https://doi.org/10.1016/i.rser.2010.12.007

[11] Mousafarash, Ali, and Mohammad Ameri. "Exergy and exergo-economic based analysis of a gas turbine power generation system." Journal of Power Technologies 93, no. 1 (2013): 44-51.

[12] Oyedepo, Sunday Olayinka, R. O. Fagbenle, S. S. Adefila, and Md Mahbub Alam. "Exergy costing analysis and performance evaluation of selected gas turbine power plants." Cogent Engineering 2, no. 1 (2015): 1101048. https://doi.org/10.1080/23311916.2015.1101048

[13] Ahmed, Ahmed Hasan, Anmmar Mahmoud Ahmed, and Qussay Younis Hamid. "Exergy and Energy Analysis of 150 MW Gas Turbine Unit: A Case Study." Journal of Advanced Research in Fluid Mechanics and Thermal Sciences 67, no. 1 (2020): 186-192.

[14] Igbong, D., and D. Fakorede. "Exergoeconomic analysis of a $100 \mathrm{MW}$ unit GE Frame 9 gas turbine plant in Ughelli, Nigeria." International Journal of Engineering and Technology 4, no. 8 (2014): 463-468.

[15] Sinaga, R. H. M., and D. W. Saputra. "Performance Investigation of Geothermal Power Plant Based on Exergy and Exergoeconomic Analyses (Case Study: Sarulla Geothermal Power Plant)." In IOP Conference Series: Materials Science and Engineering, vol. 546, no. 7, p. 072006. IOP Publishing, 2019. https://doi.org/10.1088/1757899X/546/7/072006

[16] Khademi, Maryam, and Ahmad Khosravi. "Exergoeconomic analysis and optimisation of a gas-turbine power plant 
using PSO, GA and fuzzy logic system." International Journal of Exergy 19, no. 2 (2016): $259-275$. https://doi.org/10.1504/IJEX.2016.075616

[17] Moran, Michael J., Howard N. Shapiro, Daisie D. Boettner, and Margaret B. Bailey. Fundamentals of engineering thermodynamics. John Wiley \& Sons, 2010.

[18] Cengel, Yunus A., and Michael A. Boles. Thermodynamics: An Engineering Approach 6th Editon (SI Units). The McGraw-Hill Companies, Inc., New York, 2007.

[19] Bejan, Adrian, George Tsatsaronis, and Michael J. Moran. Thermal design and optimization. John Wiley \& Sons, 1995.

[20] Dev, Nikhil, and Rajesh Attri. "Exergetic analysis of combustion chamber of a combined heat and power system." In Proceedings of the National Conference on Trends and Advances in Mechanical Engineering, YMCA University of Science \& Technology, Faridabad, Haryana. 2012.

[21] Al Ansi, Ahmed Nabil, Mubarak Salem Ballaith, Hassan Ali Al Kaabi, and Zin Eddine Dadach. "Exergoeconomic Analysis of a Power Plant in Abu Dhabi (UAE)." International Journal 5, no. 6 (2015): 185-192. https://doi.org/10.5963/IJEE0506003 